\title{
Findings of Vascular Brain Injury and Structural Loss from Cranial Magnetic Resonance Imaging in Elderly American Indians: The Strong Heart Study
}

\author{
Astrid M. Suchy-Dicey ${ }^{a}$ f Dean K. Shibata ${ }^{b}$ Tara M. Madhyasthab, c \\ Thomas J. Grabowski ${ }^{\text {b-d }}$ W.T. Longstreth Jr. ${ }^{d, e}$ Dedra S. Buchwald ${ }^{a, f}$ \\ ${ }^{a}$ Initiative for Research and Education to Advance Community Health, Washington State University, ${ }^{b}$ Department \\ of Radiology, 'Integrated Brain Imaging Center, ${ }^{\mathrm{d}}$ Department of Neurology, and ${ }^{\mathrm{C} D e p a r t m e n t}$ of Epidemiology, \\ University of Washington, ${ }^{\mathrm{f} E l s o n}$ S. Floyd School of Medicine, Washington State University, Seattle, WA, USA
}

\section{Keywords}

$\mathrm{MRI} \cdot$ Infarct $\cdot$ Hemorrhage $\cdot$ White matter disease $\cdot$ Central atrophy · Cerebral atrophy · American Indians

\begin{abstract}
Background: The Cerebrovascular Disease and its Consequences in American Indians study conducted cranial MRI examination of surviving participants of the Strong Heart Study, a longitudinal cohort of elderly American Indians. Methods: Of the 1,033 recruited participants, some were unable to complete the MRI $(n=22)$, some scans were unusable due to participant motion or technical errors $(n=13)$, and one community withdrew consent after data collection $(n=209)$, leaving 789 interpretable MRI scan images. Six image sequences were obtained in contiguous slices on 1.5T scanners. Neuroradiologists graded white matter hyperintensities (WMH), sulci, and ventricles on a 0 - to 9-point scale, and recorded the presence of infarcts and hemorrhages. Intracranial, brain, hippocampal, and WMH volumes were estimated by automated image processing. Results: The median scores for graded measures were $2(\mathrm{WMH})$ and 3 (sulci, ventricles). About one-third of participants had lacunar (20\%) or other infarcts (13\%); few had hemorrhages (5.7\%). Findings of cortical atrophy were also prevalent. Statistical analyses indicated significant associations between older age and findings of
\end{abstract}

(C) 2017 S. Karger AG, Basel vascular injury and atrophy; male gender was associated with findings of cortical atrophy. Conclusions: Vascular brain injury is the likely explanation in this elderly American Indian population for brain infarcts, hemorrhages, WMH grade, and $\mathrm{WMH}$ volume. Although vascular brain injury may play a role in other findings, independent degenerative other disease processes may underlie abnormal sulcal widening, ventricular enlargement, hippocampal volume, and total brain volume. Further examination of risk factors and outcomes with these findings may expand the understanding of neurological conditions in this understudied population.

(c) 2017 S. Karger AG, Basel

\section{Introduction}

American Indians experience disproportionately high burden of cardiovascular disease and stroke, relative to other racial and ethnic groups $[1,2]$. MRI can detect subclinical or covert vascular brain injury by providing highly sensitive contrast and spatial resolution [3]. MRI of elderly participants in longitudinal cohort studies has proven useful in expanding understanding of progression of vascular brain disease, especially covert disease not associated with symptoms or signs of stroke or transient ischemic attack [4-6]. However, existing cohort studies with
KARGER

E-Mail karger@karger.com

www.karger.com/ned
Astrid M. Suchy-Dicey, PhD

Washington State University 1100 Olive Way

Suite 1200 Seattle, WA 91810 (USA)

E-Mail astrid.suchy-dicey@wsu.edu 
cranial MRI have included mostly participants of European heritage with few minorities represented, especially American Indians. The Strong Heart Study (SHS) is a longitudinal cohort study of elderly American Indians; surviving participants were invited to undergo cranial MRI imaging as part of an ancillary study, the Cerebrovascular Disease and its Consequences in American Indians (CDCAI) study, also known as the "Strong Heart Stroke Study." This report details the methods used in imaging these participants and presents baseline findings of vascular brain injury and atrophy.

\section{Methods}

\section{Participants and Procedures}

As detailed elsewhere, CDCAI is an ancillary study [7] of surviving participants of the parent SHS [8], an ongoing longitudinal cohort study of 4,549 American Indians 45-79 years of age recruited between 1989 and 1991, from 13 communities in the US Northwest Plains, Southern Plains, and Southwest. At CDCAI study baseline (2010-2013), participants (a) answered standard questionnaires, (b) underwent extensive interview, clinical, physical, and neurocognitive examinations, (c) provided biological samples for assay, and (d) and submitted to cranial MRI. Institutional and Tribal Review Boards approved all study procedures, and all participants provided written, informed consent.

Briefly, participants were contacted to establish interest and eligibility; 1956 were located, of whom 261 were incapacitated or had passed away. Of the remaining 1,695 participants, 1,403 $(82.8 \%)$ were successfully contacted; of these, 201 were found ineligible, and 169 refused participation. Thus 1,033 participants were successfully recruited, of whom $22(2.1 \%)$ were unable to complete MRI. Of the 1,011 who were scanned, $13(1.3 \%)$ were excluded due to participant motion $(n=9)$ or technical errors $(n=$ 4). After data collection was complete, one community chose to withdraw, and so 209 were later removed from analyses. Ultimately, this study encompasses 789 usable, available MRI scans in elderly American Indians from 10 communities across 3 major geographic regions of the United States [7].

\section{MRI Procedures}

Field staff screened participants for eligibility and again at the time of the scan, assessing for exclusions, including prior surgery for cerebral aneurysm; cardiac pacemaker, defibrillator, or artificial heart; cochlear implant, spinal cord stimulator, or other internal electrical devices; employment as a metal worker because of retained metal fragments, especially near the eyes; and weight of 350 pounds or more. Imaging protocols were compatible with the level of technology available at the community hospitals where the scans were performed, based on time constraints imposed by scanner use, and the limited endurance of elderly participants. Local radiologists read the scans and contacted the local medical staff who referred patients to medical care in the event of clinically relevant incidental findings. Quality control included testing and demonstration at each site of the expected image quality and adherence to the multi-site protocols.
A Siemens 1.5T Symphony scanner (Siemens Medical Solutions, Malvern, PA, USA) was used in the Northern Plains, and General Electric 1.5T Signa scanners (General Electric Healthcare, Little Chalfont Buckinghamshire, UK) were used in the Southern Plains and the Southwest. To produce similar image quality across the 3 sites and 2 scanner models, and to allow comparability with existing cohorts, pulse sequences were similar to those used by the Atherosclerosis Risk in Communities (ARIC) study and the Cardiovascular Health Study (CHS) [9-12]. Six sequences were obtained in contiguous slices: (1) sagittal T1-weighted localizer, (2) co-registered $5 \mathrm{~mm}$ axial-T1, (3) $5 \mathrm{~mm}$ axial-T2, and (4) $5 \mathrm{~mm}$ axial-T2* susceptibility-weighted images in the anterior commissure/posterior commissure plane, (5) $3 \mathrm{~mm}$ axial fluid-attenuated inversion recovery (FLAIR) images, and (6) $1.5 \mathrm{~mm}$ sagittal T1-weighted volumetric gradient echo images. Additional details regarding repetition time, echo time, inversion time, slice thickness, slice spacing, acquisition matrix, number excitations, echo train, flip angle, and field of view are included in online supplemental materials (for all online suppl. material, see www.karger.com/doi/10.1159/000459624).

\section{Image-Reading Procedures}

Study neuroradiologists were trained in the study protocols and read all scans, blinded to participants' age, gender, and clinical information. A primary reader scored all aspects of the scan, and a secondary reader also assessed the presence of brain infarcts and hemorrhages. Both neuroradiologists reviewed any scans with discrepant readings until a consensus was reached.

Brain infarcts were defined as lesions $3 \mathrm{~mm}$ or larger in maximum dimension, anywhere in the brain, with characteristic shape and absence of mass effect. Infarcts were required to have hyperintensity to gray matter on both T2-weighted images and FLAIR images to contrast with perivascular spaces, which have characteristic location and shape and demonstrate cerebrospinal fluid (CSF) intensity on all sequences but need hypointensity on T1-weighted images to distinguish them from focal white matter hyperintensities $(\mathrm{WMH})[13,14]$. Lacunar infarcts were characterized as infarct lesions $3 \mathrm{~mm}$ to $2 \mathrm{~cm}$ in maximum dimension, located in the caudate, lenticular nucleus, internal capsule, thalamus, brainstem, cerebellar white matter, centrum semiovale, or corona radiate.

Brain hemorrhages were defined based on clinical criteria as lesions anywhere in the brain, of any size, with hypointensity on gradient echo images, which are sensitive to even a small amount of old blood in the brain tissue [15]. Neuroradiologists characterized the number, size, type, and location of both infarcts and hemorrhages $[9,10]$.

Neuroradiologists also graded the severity of $\mathrm{WMH}$, sulcal widening, and ventricle enlargement using a semi-quantitative 10-point scale based on previously validated image standards for FLAIR images for WMH and T1-weighted images for sulci and ventricles $[11,16,17]$. Image readers matched each participant's scan image to the 8 standard template images used by ARIC and CHS [18] cohorts, and determined a best visual fit for severity. Grades ranged from 0 (normal) to 9 (most abnormal).

\section{Image Volumetric Estimation}

In addition to the semi-quantitative scales based on visual comparison to templates, quantitative volumes were estimated on a continuous scale for WMH, hippocampus, total brain (grey and white matter), and intracranial (IC) space. Images were visually checked at intermediate points in the process for gross misregistra- 
tions or processing failures. Such problems were corrected manually. Despite these adjustments, automated image processing for some participants failed due to low image quality or motion artifact causing errors in the automated algorithms: WMH volume $(n=$ $116)$; hippocampus volume $(n=101)$; brain volume $(n=195)$; and IC volume $(n=98)$.

The volume of WMH was calculated by segmenting $3 \mathrm{~mm}$ FLAIR images (sequence 5) using the Fuzzy Lesion Extractor (FLEX) technique [20]. In general, FLEX uses a dynamic threshold, identifying candidate WMH voxels that are brighter than the gray matter, followed by false positive detection. After noise reduction filtering and removal of hyperintense voxels, a 2-class unsupervised fuzzy $\mathrm{C}$-means clustering algorithm was applied to separate remaining voxels into either brain tissue or background-CSF. Using this method, WMH voxels are outliers in both of these clusters. After masking out these hyperintense voxels based on the membership grade from fuzzy C-means clustering, the final segmentation threshold was determined on a slice-by-slice basis. This was done by creating histograms of the voxel intensities in the masked and unmasked FLAIR images, and setting the threshold at the intensity of the first bin that contained an unequal numbers of voxels. To detect false positives, the brain was masked with the thresholded white matter template (white matter probability = 0.41 ), and hyperintensities that were not connected in $3 \mathrm{D}$ to the thresholded template were removed.

A custom white matter template was developed from the study sample using 50 randomly selected high-resolution T1-weighted images (sequence 6). First, the T1 image was transformed to Montreal Neurological Institute (MNI) 152 template saving the transform matrix. Second, the T1-weighted image was skull stripped using the functional MRI software library brain extraction tool $[20,21]$. FSL fast segmentation on the skull-stripped image transformed the white matter probabilistic mask to standard space [22]. Finally, the masks were summed and averaged to create a probabilistic template.

Hippocampal volume was measured using automated segmentation from the 3D T1-weighted images (sequence 6) with FIRST in FSL 5.0 [23] and the ENIGMA1 protocol [24]. First, a training set of manually segmented images included with the software were parameterized as surface meshes and then modeled as a point distribution. FIRST searches through linear combination of shape modes of variation for the most probable shape instance, given the observed intensities in a T1-weighted image. To accommodate partial-volume scans, the range of registration parameters was limited to -5 to +20 degrees. Images were checked at key intermediate points, such as after registrations and skull stripping, and adjustments were made at those points.

IC volume was estimated using the ENIGMA1 protocol for FSL, as follows [23]. An estimate was obtained by linear alignment of each individual brain to the MNI152 template [25]. The inverse of the determinant of the affine transformation matrix, multiplied by the template size $(1,827 \mathrm{~mL})$, provided an estimate of IC volume considered equivalent to manual correction [26]. All registrations were visually inspected and corrected where necessary to obtain an accurate affine transformation.

Total brain volume was estimated after skull stripping using cortical reconstruction implemented in version 5.3 of the FreeSurfer image analysis suite [21, 27-29]. A complete summary of this pipeline is provided online [30]. Briefly, this processing includes motion correction [31], removal of non-brain tissue using a hybrid watershed-surface deformation procedure [32], automated Talairach transformation, segmentation of the subcortical white matter and deep gray matter volumetric structures [29, 33], intensity normalization [34] tessellation of the gray matter-white matter boundary, automated topology correction [35,36], and surface deformation following intensity gradients to place optimally the gray matter-white matter and gray matter-CSF borders at the location where the greatest shift in intensity defines the transition to the other tissue class $[27,28,37]$. Therefore, brain volume measurement includes cerebellum but not ventricles, CSF, and dura.

\section{Other Measures}

Age was defined continuously and by category: $<70,70$ to $<75$, 75 to $<80$, and $\geq 80$ years. Gender was self-reported as male or female. Marital status was categorized as single (not married), current (married, partnered), or past (divorced, separated, widowed). Education and income were categorized as asked in the questionnaire: <6th grade, 7-8th grade, 9-11th grade, graduated high school, some college, bachelor's, some grad school, master's, doctorate; $<\$ 5,000 /$ year, $\$ 5,000-10,000 /$ year, $\$ 10,000-15,000 /$ year, $\$ 15,000-20,000 /$ year, $\$ 20,000-25,000 /$ year, $\$ 25,000-35,000 /$ year, $\$ 35,000-50,000 /$ year, $>\$ 50,000 /$ year, respectively. Native language speaking capacity represented bi-lingual language skills, and was assessed according to self-reported categories, including not at all, a little, moderately well, and very well.

\section{Statistical Procedures}

Participant sociodemographic characteristics were summarized as median (interquartile range, IQR) or number (percent, \%). To help interpret results as normal or abnormal, grades for white matter, sulci, and ventricles were dichotomized at grade 2 versus grade 3 or higher $[18,38,39]$ and counts of brain infracts and hemorrhages were dichotomized as absent or present. These measures were summarized as $n(\%)$. WMH volume, hippocampus volume, and total brain volume were expressed as percentage of estimated IC volume and summarized as median (IQR). All measures were stratified by male or female gender categories; Fisher's exact tests were used to test for statistical differences among strata. Scatter and local polynomial smooth plots with $95 \%$ CIs were used to evaluate associations between MRI findings and continuous age (in years) at MRI examination; the smoothing kernel function for the smoothing plots used the Epanechnikov method [40]. All statistical analyses were done using Stata version 13 (College Station, TX, USA).

\section{Results}

CDCAI participants with MRI scans $(n=789)$ had a median age of 72 years at the time of the MRI (range 64-95) and were predominantly female (Table 1). A majority were widowed, separated, or divorced, with 5\% never having been married. A majority of participants had at least some college education, but a similar proportion had family income less than $\$ 15,000$ per year. Bilingual status was split (speaking English was a study requirement), with roughly one-quarter speaking native language very well, and onethird speaking it not at all. Men and women were compa- 
Table 1. Demographic characteristics of American Indians who completed MRI examinations in the cerebrovascular disease and its consequences in American Indians study (2010-2013)

\begin{tabular}{|c|c|c|c|}
\hline & All $(n=789)$ & Women $(n=533)$ & $\operatorname{Men}(n=256)$ \\
\hline Age, years, median (IQR) ${ }^{\dagger}$ & $72(68-77)$ & $72(68-77)$ & $72(68-76)$ \\
\hline \multicolumn{4}{|l|}{ Marital status, $n(\%)$} \\
\hline Single & $43(5.5)$ & $22(4.1)$ & $21(8.2)$ \\
\hline Current & $296(37.5)$ & $152(28.5)$ & $144(56.3)$ \\
\hline Past & $450(57.0)$ & $359(67.4)$ & $91(35.6)$ \\
\hline \multicolumn{4}{|l|}{ Education, $n(\%)$} \\
\hline$<6$ th grade & $13(1.7)$ & $8(1.5)$ & $5(2.0)$ \\
\hline $7-8$ th grade & $46(5.8)$ & $31(5.8)$ & $15(5.9)$ \\
\hline $9-11$ th grade & $96(12.2)$ & $71(13.3)$ & $25(9.8)$ \\
\hline HS diploma/GED & $197(25.0)$ & $131(24.6)$ & $66(25.8)$ \\
\hline Some college & $317(40.2)$ & $218(40.9)$ & $99(38.7)$ \\
\hline $\mathrm{BA} / \mathrm{BS}$ degree & $69(8.8)$ & $49(9.2)$ & $20(7.8)$ \\
\hline Some grad school & $10(1.3)$ & $4(0.8)$ & $6(2.3)$ \\
\hline MA/MS degree & $36(4.6)$ & $21(3.9)$ & $15(5.9)$ \\
\hline Doctorate degree & $5(0.6)$ & 0 & $5(2.0)$ \\
\hline \multicolumn{4}{|l|}{ Household Income, $n(\%)$} \\
\hline$<\$ 5,000 /$ year & $91(11.7)$ & $65(12.3)$ & $26(10.3)$ \\
\hline$\$ 5,000-10,000 /$ year & $147(18.9)$ & $107(20.3)$ & $40(15.9)$ \\
\hline$\$ 10,000-15,000 /$ year & $138(17.7)$ & $102(19.4)$ & $36(14.3)$ \\
\hline$\$ 15,000-20,000 /$ year & $91(11.7)$ & $69(13.1)$ & $22(8.7)$ \\
\hline$\$ 20,000-25,000 /$ year & $87(11.2)$ & $54(10.3)$ & $33(13.1)$ \\
\hline$\$ 25,000-35,000 /$ year & $86(11.0)$ & $57(10.8)$ & $29(11.5)$ \\
\hline$\$ 35,000-50,000 /$ year & $67(8.6)$ & $39(7.4)$ & $28(11.1)$ \\
\hline$>\$ 50,000 /$ year & $72(9.2)$ & $34(6.5)$ & $38(15.1)$ \\
\hline \multicolumn{4}{|c|}{ Native language speaking capacity, $n(\%)$} \\
\hline Not at all & $254(32.3)$ & $171(32.1)$ & $83(32.6)$ \\
\hline A little & $227(28.8)$ & $143(26.8)$ & $84(32.9)$ \\
\hline Moderately & $97(12.3)$ & $70(13.1)$ & $27(10.6)$ \\
\hline Very well & $210(26.7)$ & $149(28.0)$ & $61(23.9)$ \\
\hline \multicolumn{4}{|l|}{ History of stroke, $n(\%)$} \\
\hline Self-reported & $62(7.9)$ & $44(8.3)$ & $18(7.0)$ \\
\hline \multicolumn{4}{|l|}{ History of heart attack, $n(\%)$} \\
\hline Self-reported & $106(13.4)$ & $56(10.5)$ & $50(19.5)$ \\
\hline \multicolumn{4}{|l|}{ Hypertension } \\
\hline High BP or meds & $636(80.6)$ & $429(80.5)$ & $207(80.9)$ \\
\hline \multicolumn{4}{|l|}{ Diabetes } \\
\hline High FPG or meds & $389(49.3)$ & $267(50.1)$ & $122(47.7)$ \\
\hline \multicolumn{4}{|l|}{ Dyslipidemia } \\
\hline High LDL or meds & $318(40.3)$ & $208(39.0)$ & $110(43.0)$ \\
\hline \multicolumn{4}{|l|}{ Chronic kidney disease } \\
\hline MDRD eGFR $<60$ & $209(26.5)$ & $154(28.9)$ & $55(21.5)$ \\
\hline
\end{tabular}

${ }^{\dagger}$ Few participants aged $<65$ years $(n=3)$ or $>85$ years $(n=30)$. Women mean age $73.2($ SD 6.1$)$. Men mean age 72.6 (SD 5.3).

rable in most characteristics, although men were more likely to be currently married, have somewhat higher household income, and have a self-reported history of heart attack.

Some participants underwent MRI scans, but these scans were not interpretable. Comparing participants with $(n=789)$, without interpretable $(n=13)$, and without any $(n=22)$ MRI scans (online suppl. Table 1$)$, most sociodemographic characteristics were substantively similar, with a few exceptions. More participants with unusable images or who were ineligible were in the lower income and education categories or had prior self-report-
42

Neuroepidemiology 2017;48:39-47 DOI: $10.1159 / 000459624$
Suchy-Dicey/Shibata/Madhyastha/ Grabowski/Longstreth Jr./Buchwald 
ed stroke. Participants with a failed scan were more likely to have reported prior heart attack, hypertension, diabetes, and kidney disease but less dyslipidemia.

Incidental findings were detected in a few participants, including hemorrhage $(n=12)$, neoplasm $(n=10)$, congenital disorder $(n=1)$, hydrocephalus $(n=3)$, other $(n=19)$, and vascular $(n=50)$. Hemorrhages were nearly all microhemorrhages but also included 1-2 of each of the following: amyloid angiopathy, cavernous malformations, and holohemispheric subdural hematoma. Suspected neoplasms included 1-4 each of the following: meningioma, pituitary adenoma, lipoma, carniopharyngioma, and unidentified deep mass. Congenital finding was hypoplastic splenium. Other findings included 8 with evidence of contusion/trauma/fracture, 4 craniotomy/burr hole, and 1-2 of each of the following: arachnoid cyst, cervical fusion, and Chiari malformation. Incidental vascular findings overlapped with graded findings of vascular brain injury; of the 50 incidental vascular findings, 29 were lacunar infarcts, 15 were other infarcts $>3 \mathrm{~mm}$, and 27 participants had white matter lesions of CHS grade $\geq 3$.

Distribution of grades for white matter, ventricles, and sulci is shown in Figure 1 and represent prevalent disease with mean and mode of each measure between grades 2 (normal) and 3 (abnormal). Only 7 participants had grade 0 (no evidence of disease) in terms of white matter; all participants had grade 1 or higher in sulci and ventricles. About one third of participants had brain infarcts (lacune or other type) or white matter grade $\geq 3$, whereas hemorrhages were present only in about $5 \%$ (Table 2). Volumetric evaluation of total WMH was approximately $0.5 \%$ of IC volume, with interquartile ranges between 0.2 and $0.8 \%$. None of these findings of vascular brain injury was statistically different, comparing men with women.

However, findings of cortical atrophy had substantial prevalence and were statistically different between men and women, with men having more extreme findings for each measure. About $60 \%$ of women showed abnormal grade for ventricle enlargement or sulcal widening, whereas $75-80 \%$ of men had such findings (both Fisher's exact $p<0.001)$. Median volumetric estimations of hippocampus, as percentage of IC volume, were $0.6 \%$ in women and $0.5 \%$ in men; similar estimates for whole brain were $78.3 \%$ in women and $76.1 \%$ in men (both Wilcoxon rank sum $p$ value $<0.001$ ).

Visual examination of scatter plots with local polynomial smoothed regression lines and 95\% CIs of age (yaxis) in relation with cranial MRI findings (x-axes) showed positive associations between higher age and

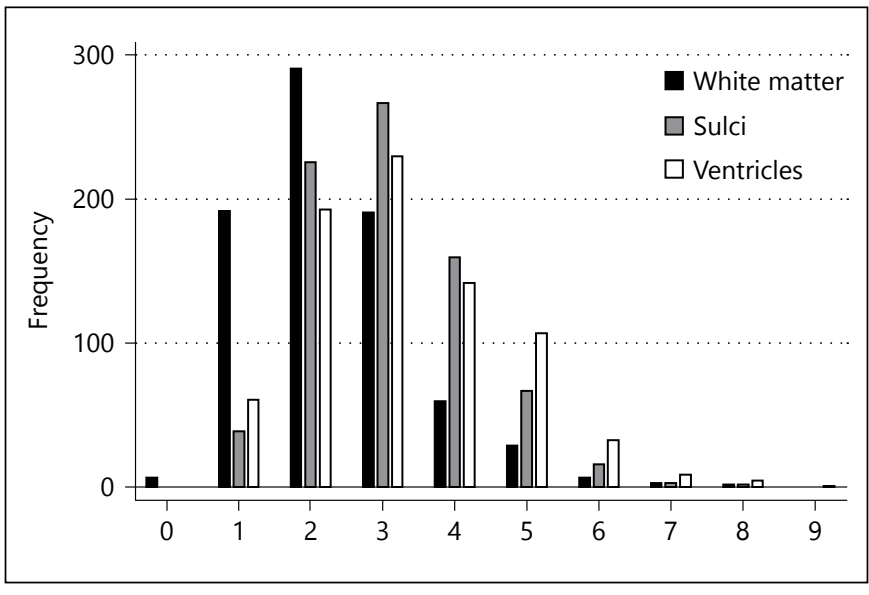

Fig. 1. Distribution of graded, cranial MRI findings in elderly American Indians.

more extreme findings of graded white matter, ventricles, and sulcal widening (Fig. 2), although the most extreme grades (>grade 6) had fewer data points and therefore larger $95 \%$ CIs. Similar examinations of age in relation to volumetric estimations showed positive associations between age (x-axes) and increased WMH volume or decreased hippocampus and brain volumes (online suppl. material), although findings for hippocampus were subtle and the most extreme age range for all associations ( $>85$ years) had few observations, resulting in larger 95\% CIs than younger age ranges ( $<85$ years).

\section{Discussion}

This is the first large cohort study examining the prevalence of cranial MRI findings among American Indians. These imaging data are comprehensive, precise, and sensitive to subclinical injury and disease [7]. Vascular brain injury is the likely explanation in this elderly population for some of the MRI findings, including brain infarcts, hemorrhages, WMH grade, and WMH volume. Although vascular brain injury may play a role in other findings, independent degenerative disease processes or other processes may underlie grades for sulcal widening and ventricle enlargement and volumes for the hippocampi and total brain combining white and gray matter. Examining the distribution of graded MRI measures indicates that $\mathrm{WMH}$ - a measure of vascular brain injury - is graded less extremely than either sulci or ventricles - both measures of atrophy. If abnormal is defined as a grade of 3 or more, a majority of participants would be considered 
Table 2. Cranial MRI findings of vascular brain injury and brain atrophy in elderly American Indians

\begin{tabular}{|c|c|c|c|c|}
\hline \multicolumn{5}{|c|}{ Grade $\geq 3$ (abnormal), $n(\%)$} \\
\hline WMH & $292(37.3)$ & $204(38.7)$ & $88(34.5)$ & 0.27 \\
\hline Ventricles & $527(67.5)$ & $323(61.4)$ & $204(80.0)$ & $<0.001$ \\
\hline Sulci & $515(66.0)$ & $325(61.9)$ & $190(74.5)$ & $<0.001$ \\
\hline \multicolumn{5}{|c|}{ Presence of lesions, $n(\%)$} \\
\hline Lacunar infarcts & $182(23.1)$ & $134(25.2)$ & $48(18.8)$ & 0.05 \\
\hline Hemorrhages & $45(5.7)$ & $32(6.1)$ & $13(5.1)$ & 0.63 \\
\hline \multicolumn{5}{|c|}{ Volume, as \% intracranial, median (IQR) } \\
\hline WMH & $0.48(0.21-0.79)$ & $0.50(0.21-0.78)$ & $0.46(0.23-0.80)$ & 0.70 \\
\hline Hippocampus & $0.55(0.50-0.60)$ & $0.57(0.52-0.61)$ & $0.52(0.47-0.57)$ & $<0.001$ \\
\hline Brain & $77.7(74.8-80.1)$ & $78.3(75.7-80.6)$ & $76.1(72.7-78.8)$ & $<0.001$ \\
\hline
\end{tabular}

MRI findings are not mutually exclusive; lacunar and other infarcts may both be present in an individual participant.

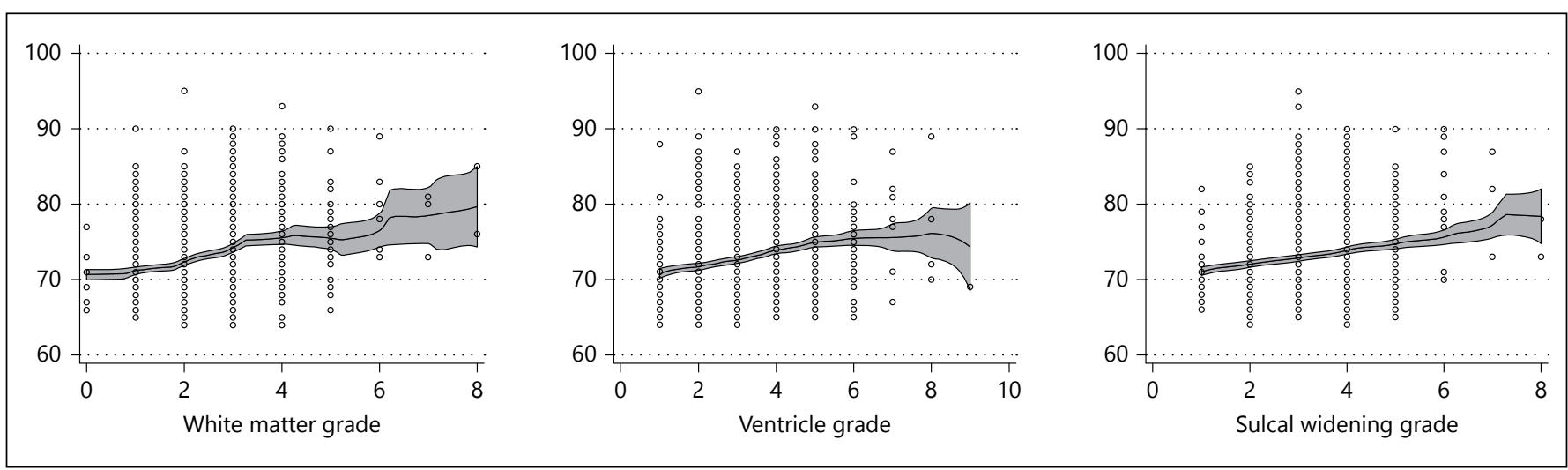

Fig. 2. Distribution of graded MRI findings in relation to age at MRI examination in elderly American Indians.

normal $(<3)$ for vascular brain injury but abnormal $(\geq 3)$ for measures of atrophy.

Vascular brain injury affected approximately onethird of participants, but with no observed differences between males and females. In contrast, findings of atrophy were observed for a majority of women and two-thirds of men, with clear statistical differentiation by gender. Age was correlated positively with both vascular brain injury and atrophy, suggesting a progressive or degenerative nature of these findings of brain disease.

This study is not without limitation. First, the selection was among survivors of the parent study, so survival from original recruitment (1989-1991) to MRI recruitment (2010-2013) may be affected by clinical measures, risk factors, and comorbid conditions. If present, such selection could lead to an underestimation of the prevalence of the most extreme conditions, since the sickest participants would be the least likely to participate. Future research using these data may use inverse probability weighting to empirically evaluate the effects that selection pressure might have on statistical associations with MRI findings.

Although increased survival among women in this population may contribute to gender comparisons including relatively more healthy men, we did not detect many differences in demographic, socioeconomic, or cardiovascular risk factors between men and women. Men and women were comparable in most characteristics, with slight variations in self-reported prior stroke, kidney disease, diabetes, dyslipidemia, and Native language use. Men were also more likely to have current marital status, higher income and education, and a self-reported history of heart attack (19.5\% men vs. $10.5 \%$ women). If these differences did contribute to men being healthier than women, on average, our findings that prevalence of vascular 
brain injury was similar in men and women and that men had more extreme cortical loss than women may be conservatively biased toward the null.

In addition, our study excluded those who were unable to complete MRI, such as inability to sit still, or who had contraindicating conditions such as pacemaker or metal implants. Of the number found eligible and able to appear at the MRI examination $(n=1,011), 13(1.3 \%)$ had unusable scans based on motion artifact or other technical difficulties. However, these numbers of failed imaging are very small, and most did not appear different in major demographic and clinical characteristics from those with successful MRI.

Both semi-quantitative (graded) and quantitative (volumetric) approaches to evaluating MRI for abnormal findings were used because, although volumetric measures have the advantage of objective precision and accuracy, semi-quantitative scoring offers robustness against measurement error in a community hospital setting using different scanners on elderly participants prone to motion artifact [41]. Some MRI evaluations and protocols, including functional MRI or sequences such as diffusion tensor imaging, were not feasible in this setting due to the availability of resources and training in such techniques.

Local radiologists identified incidental findings, and local medical staff referred participants to specialists if deemed appropriate; the ethical issues and clinical relevance of such findings are complex [42]. An evaluation of incidental findings in a predominantly Caucasian population included $7 \%$ with infarct, $1.6 \%$ with benign tumor such as meningioma, lipoma, and pituitary adenoma; $1.1 \%$ with arachnoid cyst; among other findings [42]. In contrast, incidental findings in CDCAI included $4.5 \%$ with infarct; $1 \%$ benign neoplasm; and $0.3 \%$ arachnoid cyst, among other findings. The distributions of incidental findings on cranial MRI between these 2 very different populations appear similar, although future research may distinguish differences with more sensitive, specific statistical methods.

Detection of rare abnormalities is a challenge even when sensitive techniques such as MRI are used. The number needed to scan varies depending on the prevalence of the specific finding; any neoplasia requires an estimated 143 scans, whereas arteriovenous malformations require more than 2000 [43]. However, these estimates are based on studies that included mostly middleaged Caucasians, whereas American Indian populations are known to have a much higher burden of stroke, and perhaps also of findings from cranial MRI $[1,2,42]$. Our study, with nearly 1,000 scans, is likely to represent stable estimates of prevalence, except for very rare conditions.
American Indians experience disproportionately high burden of cardiovascular disease and stroke, relative to other racial and ethnic groups $[1,2]$. By providing highly sensitive contrast and spatial resolution, MRI can detect subclinical or covert vascular brain injury [3]. Findings from cranial MRI may be defined in several ways, and different MRI measures have independent associations with manifestations of cognitive impairment, loss of motor function, and depression, and with subsequent risk of stroke, dementia, and death - although some of these associations are yet to be clearly established for non-Caucasians $[4,44,45]$.

In conclusion, the CDCAI study conducted extensive MRI data collection as part of larger neurological examinations and data collection efforts among elderly American Indian participants of the SHS [7]. Future research may evaluate cognitive conditions associated with vascular brain injury and cortical or subcortical loss in this elderly American Indian population. Evidence from MRI of vascular brain injury and brain atrophy is common, and positively associated with age and gender. These descriptive evaluations of cranial MRI findings support the comprehensive understanding of stroke and related neurological conditions in this understudied population.

\section{Acknowledgments}

This work was supported by funding from the National Heart Lung and Blood Institute, HL093086 (Buchwald; CDCAI), HL065520 (Cole; SHFS), and HL041654 (Lee; SHS IV).

The opinions expressed in this paper are those of the author(s) and do not necessarily reflect the views of the Indian Health Service (IHS).

We wish to thank all study participants.

\section{Financial Disclosures}

The authors have no interests to disclose.

References

Neuroepidemiology 2017;48:39-47

1 Centers for Disease Control and Prevention (CDC): Disparities in deaths from stroke among persons aged $<75$ years - United States, 2002. MMWR Morb Mortal Wkly Rep 2002;54:477-481.

2 Centers for Disease Control and Prevention (CDC): Prevalence of Stroke - United States, 2005. MMWR Morb Mortal Wkly Rep 2007; 56:469-474.

3 Broderick DF: Neuroimaging in neuropsychiatry. Psychiatr clin North Am 2005;28: 549-566. 
4 Vermeer SE, Longstreth WT Jr, Koudstaal PJ: Silent brain infarcts: a systematic review. Lancet Neurol 2007;6:611-619.

5 Debette S, Markus HS: The clinical importance of white matter hyperintensities on brain magnetic resonance imaging: systematic review and meta-analysis. BMJ 2010; 341:c3666.

6 Fanning JP, Wesley AJ, Wong AA, Fraser JF: Emerging spectra of silent brain infarction. Stroke 2014;45:3461-3471.

7 Suchy-Dicey AM, Shibata D, Best LG, Verney SP, Longstreth WT Jr, Lee ET, Okin PM, Devereux R, O'Leary M, Ali T, Jensen PN, Muller C, Nelson LA, Rhoades E, Madhyastha T, Grabowski TJ, Beauchamp N, Umans JG, Buchwald D: Cranial magnetic resonance imaging in elderly American Indians: design, methods, and implementation of the cerebrovascular disease and its consequences in American Indians Study. Neuroepidemiology 2016;47:67-75.

8 Lee ET, Welty TK, Fabsitz R, Cowan LD, Le NA, Oopik AJ, Cucchiara AJ, Savage PJ, Howard BV: The strong heart study. A study of cardiovascular disease in American Indians: design and methods. Am J Epidemiol 1990; 132:1141-1155.

9 Bryan RN, Manolio TA, Schertz LD, Jungreis C, Poirier VC, Elster AD, Kronmal RA: A method for using MR to evaluate the effects of cardiovascular disease on the brain: the cardiovascular health study. AJNR Am J Neuroradiol 1994;15:1625-1633.

10 Manolio TA, Kronmal RA, Burke GL, Poirier V, O'Leary DH, Gardin JM, Fried LP, Steinberg EP, Bryan RN: Magnetic resonance abnormalities and cardiovascular disease in older adults. The cardiovascular health study. Stroke 1994;25:318-327.

11 Liao D, Cooper L, Cai J, Toole JF, Bryan NR, Hutchinson RG, Tyroler HA: Presence and severity of cerebral white matter lesions and hypertension, its treatment, and its control. The ARIC study. Atherosclerosis risk in communities study. Stroke 1996;27:2262-2270.

12 Knopman DS, Mosley TH, Catellier DJ, Sharrett AR; Atherosclerosis Risk in Communities (ARIC) Study: Cardiovascular risk factors and cerebral atrophy in a middle-aged cohort. Neurology 2005;65:876-881.

13 Bryan RN, Cai J, Burke G, Hutchinson RG, Liao D, Toole JF, Dagher AP, Cooper L: Prevalence and anatomic characteristics of infarct-like lesions on MR images of middleaged adults: the atherosclerosis risk in communities study. AJNR Am J Neuroradiol 1999;20:1273-1280.

14 Windham BG, Griswold ME, Shibata D, Penman A, Catellier DJ, Mosley TH Jr: Covert neurological symptoms associated with silent infarcts from midlife to older age: the atherosclerosis risk in communities study. Stroke 2012;43:1218-1223.

15 Tsushima Y, Aoki J, Endo K: Brain microhemorrhages detected on $\mathrm{T}^{*}$-weighted gradient-echo MR images. AJNR Am J Neuroradiol 2003;24:88-96.
16 Knopman DS, Penman AD, Catellier DJ, Coker LH, Shibata DK, Sharrett AR, Mosley TH Jr: Vascular risk factors and longitudinal changes on brain MRI: the ARIC study. Neurology 2011;76:1879-1885.

17 Price TR, Manolio TA, Kronmal RA, Kittner SJ, Yue NC, Robbins J, Anton-Culver H, O'Leary DH: Silent brain infarction on magnetic resonance imaging and neurological abnormalities in community-dwelling older adults. The Cardiovascular Health Study. CHS Collaborative Research Group. Stroke 1997;28:1158-1164.

18 Longstreth WT Jr., Manolio TA, Arnold A, Burke GL, Bryan N, Jungreis CA, Enright PL, O'Leary D, Fried L: Clinical correlates of white matter findings on cranial magnetic resonance imaging of 3301 elderly people. The Cardiovascular Health Study. Stroke 1996;27:1274-1282.

19 Gibson E, Gao F, Black SE, Lobaugh NJ: Automatic segmentation of white matter hyperintensities in the elderly using FLAIR images at 3T. J Magn Reson Imaging 2010;31:1311-1322.

20 Jenkinson MD, Smith TS, Joyce K, Fildes D, du Plessis DG, Warnke PC, Walker C: MRS of oligodendroglial tumors: correlation with histopathology and genetic subtypes. Neurology 2005;64:2085-2089.

21 Smith SM: Fast robust automated brain extraction. Hum Brain Mapp 2002;17:143-155.

22 Zhang Y, Brady M, Smith S: Segmentation of brain MR images through a hidden Markov random field model and the expectationmaximization algorithm. IEEE Trans Med Imaging 2001;20:45-57.

23 Patenaude B, Smith SM, Kennedy DN, Jenkinson M: A bayesian model of shape and appearance for subcortical brain segmentation. Neuroimage 2011;56:907-922.

24 Stein JL, Medland SE, Vasquez AA, Hibar DP, Senstad RE, Winkler AM, Toro R, Appel K, Bartecek R, Bergmann $\varnothing$, Bernard M, Brown AA, Cannon DM, Chakravarty MM, Christoforou A, Domin M, Grimm O, Hollinshead M, Holmes AJ, Homuth G, Hottenga JJ, Langan C, Lopez LM, Hansell NK, Hwang KS, Kim S, Laje G, Lee PH, Liu X, Loth E, Lourdusamy A, Mattingsdal M, Mohnke S, Maniega SM, Nho K, Nugent AC, O'Brien C, Papmeyer M, Pütz B, Ramasamy A, Rasmussen J, Rijpkema M, Risacher SL, Roddey JC, Rose EJ, Ryten M, Shen L, Sprooten E, Strengman E, Teumer A, Trabzuni D, Turner J, van Eijk K, van Erp TG, van Tol MJ, Wittfeld K, Wolf C, Woudstra S, Aleman A, Alhusaini S, Almasy L, Binder EB, Brohawn DG, Cantor RM, Carless MA, Corvin A, Czisch M, Curran JE, Davies G, de Almeida MA, Delanty N, Depondt C, Duggirala R, Dyer TD, Erk S, Fagerness J, Fox PT, Freimer NB, Gill M, Göring HH, Hagler DJ, Hoehn D, Holsboer F, Hoogman M, Hosten N, Jahanshad N, Johnson MP, Kasperaviciute D, Kent JW Jr, Kochunov P, Lancaster JL, Lawrie SM, Liewald DC, Mandl R, Matarin M, Mattheisen M, Meisenzahl E, Melle I, Moses EK, Mühleisen TW, Nauck M, Nöthen MM,
Olvera RL, Pandolfo M, Pike GB, Puls R, Reinvang I, Renteria ME, Rietschel M, Roffman JL, Royle NA, Rujescu D, Savitz J, Schnack HG, Schnell K, Seiferth N, Smith C, Steen VM, Valdés Hernández MC, Van den Heuvel M, van der Wee NJ, Van Haren NE, Veltman JA, Völzke H, Walker R, Westlye LT, Whelan CD, Agartz I, Boomsma DI, Cavalleri GL, Dale AM, Djurovic S, Drevets WC, Hagoort P, Hall J, Heinz A, Jack CR Jr, Foroud TM, Le Hellard S, Macciardi F, Montgomery GW, Poline JB, Porteous DJ, Sisodiya SM, Starr JM, Sussmann J, Toga AW, Veltman DJ, Walter H, Weiner MW; Alzheimer's Disease Neuroimaging Initiative; EPIGEN Consortium; IMAGEN Consortium; Saguenay Youth Study Group, Bis JC, Ikram MA, Smith AV, Gudnason V, Tzourio C, Vernooij MW, Launer LJ, DeCarli C, Seshadri S, Cohorts for Heart and Aging Research in Genomic Epidemiology Consortium, Andreassen OA, Apostolova LG, Bastin ME, Blangero J, Brunner HG, Buckner RL, Cichon S, Coppola G, de Zubicaray GI, Deary IJ, Donohoe G, de Geus EJ, Espeseth T, Fernández G, Glahn DC, Grabe HJ, Hardy J, Hulshoff Pol HE, Jenkinson M, Kahn RS, McDonald C, McIntosh AM, McMahon FJ, McMahon KL, Meyer-Lindenberg A, Morris DW, Muller-Myhsok B, Nichols TE, Ophoff RA, Paus T, Pausova Z, Penninx BW, Potkin SG, Sämann PG, Saykin AJ, Schumann G, Smoller JW, Wardlaw JM, Weale ME, Martin NG, Franke B, Wright MJ, Thompson PM; Enhancing Neuro Imaging Genetics through Meta-Analysis Consortium: Identification of common variants associated with human hippocampal and intracranial volumes. Nat Genet 2012;44:552-561.

25 Collins DL ZA, Baare WFC, Evans AC: Animal and Insect: Improved Cortical Structure Segmentation: Information Processing in Medical Imaging, 16th International Conference. Videgrad Hungary, Springer LINK, 1999, p 1613

26 Buckner RL, Head D, Parker J, Fotenos AF, Marcus D, Morris JC, Snyder AZ: A unified approach for morphometric and functional data analysis in young, old, and demented adults using automated atlas-based head size normalization: reliability and validation against manual measurement of total intracranial volume. Neuroimage 2004;23:724-738.

27 Dale AM, Fischl B, Sereno MI: Cortical surface-based analysis. I. Segmentation and surface reconstruction. Neuroimage 1999;9:179194.

28 Fischl B, Dale AM: Measuring the thickness of the human cerebral cortex from magnetic resonance images. Proc Natl Acad Sci U S A 2000;97:11050-11055.

29 Fischl B, Salat DH, Busa E, Albert M, Dieterich $M$, Haselgrove $C$, van der Kouwe A, Killiany R, Kennedy D, Klaveness S, Montillo A, Makris N, Rosen B, Dale AM: Whole brain segmentation: automated labeling of neuroanatomical structures in the human brain. Neuron 2002;33:341-355. 
30 FreeSurfer: Cortical Reconstruction and Volumetric Segmentation as Performed Using the Freesurfer Image Analysis Suite, Center for Biomedical Imaging, Harvard University, 2016.

31 Reuter M, Rosas HD, Fischl B: Highly accurate inverse consistent registration: a robust approach. Neuroimage 2010;53:1181-1196.

32 Ségonne F, Dale AM, Busa E, Glessner M, Salat D, Hahn HK, Fischl B: A hybrid approach to the skull stripping problem in MRI. Neuroimage 2004;22:1060-1075.

33 Fischl B, Salat DH, van der Kouwe AJ, Makris N, Segonne F, Quinn BT, Dale AM: Sequenceindependent segmentation of magnetic resonance images. Neuroimage 2004;23(suppl 1):S69-S84

34 Sled JG, Zijdenbos AP, Evans AC: A nonparametric method for automatic correction of intensity nonuniformity in MRI data. IEEE Trans Med imaging 1998;17:87-97.

35 Fischl B, Liu A, Dale AM: Automated manifold surgery: constructing geometrically accurate and topologically correct models of the human cerebral cortex. IEEE Trans Med imaging 2001;20:70-80.

36 Ségonne F, Pacheco J, Fischl B: Geometrically accurate topology-correction of cortical sur- faces using nonseparating loops. IEEE Trans Med imaging 2007;26:518-529.

37 Dale AM, Sereno MI: Improved localizadon of cortical activity by combining EEG and MEG with MRI cortical surface reconstruction: a linear approach. J cogn Neurosci 1993; 5:162-176.

38 Shibata D, Tillin T, Beauchamp N, Heasman J, Hughes AD, Park C, Gedroyc W, Chaturvedi $\mathrm{N}$ : African Caribbeans have greater subclinical cerebrovascular disease than Europeans: this is associated with both their elevated resting and ambulatory blood pressure and their hyperglycaemia. J Hypertens 2013;31:2391-2399.

39 Mosley TH Jr., Knopman DS, Catellier DJ, Bryan N, Hutchinson RG, Grothues CA, Folsom AR, Cooper LS, Burke GL, Liao D, Szklo M: Cerebral MRI findings and cognitive functioning: the atherosclerosis risk in communities study. Neurology 2005;64:2056-2062.

40 Epanechnikov VA: Non-parametric estimation of a multivariate probability density. Theory Probab Appl 1969;14:153-158.

41 Kapeller P, Barber R, Vermeulen RJ, Adèr H, Scheltens P, Freidl W, Almkvist O, Moretti M, del Ser T, Vaghfeldt P, Enzinger C, Barkhof F, Inzitari D, Erkinjunti T, Schmidt R,
Fazekas F, European Task Force of Age Related White Matter Changes: Visual rating of age-related white matter changes on magnetic resonance imaging: scale comparison, interrater agreement, and correlations with quantitative measurements. Stroke 2003;34: 441-445.

42 Vernooij MW, Ikram MA, Tanghe HL, Vincent AJ, Hofman A, Krestin GP, Niessen WJ, Breteler MM, van der Lugt A: Incidental findings on brain MRI in the general population. N Engl J Med 2007;357:1821-1828.

43 Morris Z, Whiteley WN, Longstreth WT Jr, Weber F, Lee YC, Tsushima Y, Alphs H, Ladd SC, Warlow C, Wardlaw JM, Al-Shahi Salman $\mathrm{R}$ : Incidental findings on brain magnetic resonance imaging: systematic review and metaanalysis. BMJ 2009;339:b3016.

44 Fanning JP, Wong AA, Fraser JF: The epidemiology of silent brain infarction: a systematic review of population-based cohorts. BMC Med 2014;12:119.

45 Howard G, Wagenknecht LE, Cai J, Cooper L, Kraut MA, Toole JF: Cigarette smoking and other risk factors for silent cerebral infarction in the general population. Stroke 1998;29: 913-917. 